DOI: $10.15593 / 2224-9354 / 2021.3 .7$

УДК $316.752+316.36$

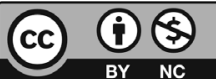

\title{
М.Н. Макарова
}

\section{РЕПРЕЗЕНТАЦИЯ «ТРАДИЦИОННЫХ ЦЕННОСТЕЙ» В РОССИЙСКОМ ПОЛИТИКО-ПУБЛИЧНОМ ПОЛЕ} (НА ПРИМЕРЕ ДИСКУРС-АНАЛИЗА СЕМЕЙНЫХ ЦЕННОСТЕЙ)

\begin{abstract}
Рассмотрены основные подходы к исследованию традиционных ценностей. В рамках социально-философского анализа выявлены такие характеристики традиционных ценностей, как относительная неизменность, связь с прошлым, направленность на поддержание социального согласия. Социологическое измерение может быть представлено как группа ценностей, характерная для различных социальных или культурных групп и как характеристика определенного типа установок, исторически обусловленных и связанных с прошлым. Политико-идеологический аспект предполагает рассмотрение традиционных ценностей как основы социально-политического дискурса, предназначенного для формирования идеологии и авторитета власти, социальной мобилизации и пропаганды. Для анализа политических текстов, содержащих презентацию образа семьи в контексте традиционных ценностей, были использованы такие методы, как контент-анализ и критический дискурс-анализ. Анализ показал, что в документах, презентующих позиции представителей власти, наиболее часто встречаются оппозиции, связанные с трудностями социальной поддержки семьи и наследием прошлого. В документах, содержащих мнения общественности, в основном говорится о западных угрозах в виде пропаганды нетрадиционных отношений, гендерного равенства и вмешательства в дела семьи. Более сдержанное использование оппозиций или их отсутствие в официальном дискурсе говорит о том, что он транслирует в основном «положительное представление себя», в то время как дискурс гражданского общества более активен в демонстрации угроз традиционным ценностям, т.е. в основном транслирует «отрицательное представление других».

Ключевые слова: традиционные ценности, семья, брак, критический дискурс-анализ.
\end{abstract}

Введение. Понятие «традиционные ценности» в последнее время приобретает все большую актуальность в российском публичном пространстве в связи с необходимостью повышения роли объединяющих компонентов для формирования общероссийской идеологии. В то же время, несмотря на постулируемую «очевидность» категории «традиционные ценности», ее смысл остается достаточно размытым и требует дополнительных исследований. Также следует отметить, что категория «традиционные ценности» имеет неоднозначную интерпретацию в научных работах и нуждается в конкретизации, особенно с точки зрения ее взаимосвязи с идеологией, которая часто «наслаивается» на исследования.

В рамках настоящего исследования традиционные ценности будут рассмотрены в трех основных аспектах: 1) социально-философский (выявление наиболее общих признаков и социальных функций феномена); 2) социологи-

(C) Макарова М.Н., 2021

Макарова Марина Николаевна - д-р социол. наук, доцент, профессор кафедры социологии ФГБОУ ВО «Удмуртский государственный университет», e-mail: makmar11@mail.ru. 
ческий (характеристики установок, характерных для определенных социальных групп); 3) идеологический (механизмы, служащие для формирования определенных взглядов и усиления существующего политического режима).

В практиках современного общества эти аспекты категории «традиционные ценности» тесно взаимосвязаны, отчего в научных исследованиях они также смешиваются, что приводит к некоторой сложности и неоднозначной оценке этого феномена. Поскольку в связи с повышением роли традиционных ценностей в формировании российской идеологии, в настоящей работе мы попытаемся проследить взаимосвязь всех трех аспектов и показать, каким образом первые два концепта могут быть использованы для анализа третьего. В результате мы попытаемся разработать основные принципы анализа идеологических и политических дискурсов, позиционирующих «традиционные ценности» как инструмент идеологического воздействия. И наконец, мы попытаемся сформировать исследовательские категории для проведения критического дискурс-анализа репрезентации традиционных семейных ценностей в российском публичном поле последних лет.

Теоретические концепты традиционных ценностей. В рамках социально-философского анализа выявляются наиболее абстрактные принципы понимания традиционных ценностей. Важный признак традиционных ценностей - их относительная неизменность, стабильность. С точки зрения Хобсбаума, основной признак традиции - это их относительная инвариантность. В этой связи традиционные ценности часто используются для обоснования консервативных взглядов [1, с. 57]. Другой признак «традиционности» связан с универсальностью, которая восходит к идеям «естественного права», в содержании которого акцент делается на приоритете разума и свободы человека, его высокого статуca, достоинства, неотъемлемых прав людей. Согласно Всеобщей декларации прав человека, важнейшей традиционной ценностью человечества, определяющей развитие и индивида, и всего общества в целом, является достоинство личности. Также к идее прав человека относятся нравственная всеобщность, поскольку такие права принадлежат всем людям вообе «просто потому, что они являются людьми», и «международная нормативная универсальность» [2].

Другой признак традиционных ценностей - это их связь с прошлым и преемственность передачи традиций через поколения. Благодаря использованию традиций прошлого формируются возможности для избирательного приспособления наследия прошлого для нужд современности [1, с. 13].

Все вышеперечисленные характеристики традиционных ценностей предусматривают их основную функцию - достижение социального согласия, усиление социальных связей в группе. Групповая идентичность, основанная на общем социальном прошлом и значимом сохраняемом наследии, способствует социальной интеграции и может провоцировать конфликты в случае внешней угрозы групповым ценностям и символическим объектам наследия [3]. 
Социологическое измерение традиционных ценностей связано со специфической группой социальных представлений, установок и может быть рассмотрено в двух аспектах: с одной стороны, как группа ценностей, характерная для различных социальных или культурных групп (этнических, религиозных и т.д.), с другой - как характеристика определенного типа установок, исторически обусловленных и связанных с прошлым, как правило, противопоставленная модернистским или иным ценностям, связанным с современными обществами. Таким образом, если первый вид традиционных ценностей более тяготеет к противопоставлению «локальное - глобальное», то вторая - к противопоставлению «старое - новое».

В первом случае традиционные ценности рассматриваются в рамках проблемы культурной идентичности как противоположности глобализационным тенденциям. Согласно Р. Робертсону, одному из теоретиков глобализации, усиление этих тенденций обострили проблему «универсализма - партикуляризма» как отражение дихотомии глобального и локального. Традиции как верования, ценности и практики, передающиеся из поколения в поколение, обусловлены историческими, культурными и социальными условиями конкретных сообществ (этносов, территорий, конфессий и др.). Они позволяют сообществам и индивидам не только чувствовать себя более безопасно и эффективно, но и формировать свою идентичность и принадлежность к определенному сообществу и типу ценностей [4, р. 38].

Вторая концепция традиционных ценностей делает акцент на том, что они прежде всего являются наследием прошлого и основаны на теориях модернизации. В наиболее широком аспекте модернизация понимается как процесс развития западных обществ, в соответствии с которым должны изменяться остальные общества и страны. В основном этот процесс предусматривает развитие экономических, прежде всего рыночных, и политических, прежде всего демократических институтов [5, p. 22].

Таким образом, социологическое измерение выявило определенные паттерны традиционных ценностей. Первый из них связан с традициями сообществ (этнических, религиозных), которые необходимо учитывать при исследовании как на глобальном, так и на локальном уровне [6, p. 4]. Второй паттерн, связанный с тенденциями модернизации, выявил относительно универсальные характеристики традиционных ценностей в противопоставлении современным [7]. В качестве наиболее важных из них, обозначенных в ряде методик, является преобладание коллективистских ценностей над индивидуалистскими, одобрение определенных форм неравенства, в частности, на уровне отношений в семье (патриархальные отношения) или гендерных отношений (неприемлемость абортов или высокостатусных позиций женщины), политических отношений (уважение к власти, низкий уровень политического участия), консерватизм (осторожное отношение к инновациям), ценности выживания и безопасности [8, с. 57]. Эти 
концепты могут в дальнейшем использоваться как «маркеры» традиционных ценностей, однако согласно исследованиям они постоянно нуждаются в контекстуальной ревизии.

Для целей нашего исследования интересным представляется третий - политико-идеологический аспект понимания традиционных ценностей, в рамках которого они рассматриваются как основа для социально-политического дискурса, предназначенного для формирования идеологии и авторитета власти, социальной мобилизации и пропаганды.

Одной из теорий, объясняющей этот аспект, является концепция «изобретенной традиции» Эрика Хобсбаума.

Согласно Хобсбауму, формирование и поддержание традиций становится символическим инструментом власти, механизмом культивирования идеологических принципов и определенного социального порядка и коллективной идентичности. Механизм «повторяемости» помогает не только поддерживать старые, но и формировать новые традиции посредством формализации и ритуализации [1, с. 51]. Одним из условий формирования «новых традиций» является ситуация преобразования общества, в том числе в процессе модернизации. В подобных случаях происходит «возрождение» определенных общественных институтов: этнических сообществ, церкви, общественно-политических структур. Хобсбаум подчеркивал важность изучения «изобретенных традиций» для историков прежде всего для изучения «интереса современного человека к прошлому». Вместе с тем этот интерес должен стать предметом изучения представителями самых различных социальных наук, изучающих современные социальные ценности и практики в их взаимосвязи с «традицией», понимаемой в самом широком смысле.

Концепт «традиционных ценностей» проявляется в публичных дискуссиях, мнениях, репрезентирующих точки зрения и социальные отношения различных социальных групп и институтов, т.е. в дискурсе. Тео ван Дейк определяет дискурс как коммуникативное событие, происходящее между говорящим, слушающим (наблюдателем и др.) в процессе коммуникативного действия в определенном временном, пространственном и прочем контексте [9, с. 48]. В работах Нормана Фейкло дискурс - использование языка как вида социальной практики, а также как форма социальной репрезентации [10, p. 63].

Критический дискурс-анализ (КДА) помогает понять взаимосвязи с ценностями определенных социальных групп, поскольку дискурс представляет собой способ идентификации и репрезентации властных отношений, следовательно, идеологический компонент является важным. Главным принципом КДА является оппозиция «мы - они», которая проявляется в формуле «Положительное представление себя и отрицательное представление других» [11, р. 39]. Традиционные ценности часто используются для идентификации «своих» в противо- 
положность «чужим», что позволяет группе обозначать свою идентичность и устанавливать символический порядок.

В связи с тем, что, как мы выяснили, дискурс традиционных ценностей обладает высокой контекстуальностью, то его анализ нуждается в предварительной категоризации применительно к конкретным социальным условиям.

Методология исследования. Наиболее универсальной ценностью, упоминаемой как традиционная, является ценность семьи. Семья всегда определялась как основной источник передачи традиций от поколения к поколению, а поэтому поддержка роли семьи понимается как основной ресурс сохранения традиционных ценностей и социальных практик различных сообществ. Для анализа взаимосвязи концептов семьи и традиционных ценностей этого мы будем ориентироваться на три вида стратегий дискурса в рамках КДА [12, р. 201].

Презентация - способы обозначения и описания исследуемого объекта, т.е. в нашем случае семьи в ее взаимосвязи с традиционными ценностями в российском общественно-политическом и социокультурном дискурсе.

Легитимация - способы обоснования и аргументации основных характеристик и связей объекта исследования, т.е. в нашем случае - объяснение понимания роли семьи в обществе и ее характеристик в рамках концепта традиционных ценностей.

Оппозищия представляет собой основные противопоставления в рамках картины мира (топика), представляющей семью сквозь призму традиционных ценностей, например, традиционная семья - нетрадиционная семья.

Такие оппозиции не всегда явно просматриваются в структуре дискурса, однако их выделение помогает лучше понять «принцип гегемонии», основанный на «положительном представлении себя» и «отрицательном представлении других».

Для анализа дискурса семьи в концепте традиционных ценностей современной России были проанализированы публикации в СМИ и интернете за 2006-2020 гг., затрагивающие проблемы семьи и традиционных ценностей, однако большинство из них датированы 2017-2020 гг., поскольку именно в этот период концепция «традиционных семейных ценностей» и связанных с ней вопросов наиболее широко обсуждается. Всего было проанализировано 122 документа. Дискурс, представленный в этих документах, содержит публичные высказывания о традиционных семейных ценностях. Несмотря на это, его следует разделить на 2 группы:

1) официальный (властный) дискурс - программные документы, связанные с семейной политикой РФ, стенограммы речей российских политиков, представителей органов власти, в первую очередь Президента РФ, представителей министерств и ведомств, а также СМИ, содержащие их высказывания и заявления;

2) дискурс «гражданского общества» - высказывания экспертов, представителей общественных организаций (в основном, патриотических, социально ориентированных и религиозных). 


\section{Результаты исследования: дискурс «традиционных семейных ценно-} cmeй». Вначале мы рассмотрим, каким образом трактуются «традиционные семейные ценности» в публичном дискурсе современной России.

Согласно поправке к статье 114 Конституции РФ, вводится понятие «традиционные семейные ценности», которые государство обязуется укреплять и поддерживать [13]. Приоритет семейных ценностей в российской государственной политике противопоставляется, в частности, предыдущим задачам государственного строительства, когда решение проблем семьи не было первостепенным, а также условиям жизни людей в 1990-е гг., «когда проблемы у людей были другими: работы не было, с зарплатой были проблемы, пенсия с перебоями. Поэтому, наверное, и нормы, связанные с семьей, были отражены ровно так, как они сегодня записаны в статьях» [14]. Этими тенденциями объясняется также рост числа разводов, снижение рождаемости и роста социального сиротства. Поэтому в Концепции государственной семейной политики Российской Федерации на период до 2025 г. указывается на необходимость не только «сохранения», но и «восстановления» традиционных семейных ценностей [15].

Другой важный аспект предполагает защиту прав детей и социальную политику в отношении семьи с детьми как основу стабильного государства и общества.

Государственная семейная политика предполагает сохранение традиционных семейных иенностей и повыщение роли семьи в жизни общества. А традиционные семейнье иченности это, по существу, и есть семья, материнство, отиовство, детство [16].

Третий аспект, обосновывающий защиту прав детей и семей, объявляется приоритетной задачей вопреки «бюджетным ограничениям».

«И наша цель общая заключается в том, чтобы в семьях появлялось больше детей - вот это единственный выход из ситуаџии. А для этого нужно, разумеется, поддерживать семьи. Мы изыскиваем самые разные возможные вариантыл... несмотря на так называемые, я уже говорил, бюджетные ограничения...» [17].

Таким образом, «традиционные семейные ценности» ставятся в один ряд с категориями «стабильность», «единство», «сильное государство», «будущее», которые провозглашаются в качестве основных идеологических концептов последних лет, а семья понимается в качестве ключевой традиционной ценности.

Другая категория - «идеальная семья и брак в контексте традиционных ценностей». Наиболее упоминаемой категорией для характеристики идеального образа семьи является многодетная семья. Брак понимается как «союз мужчины и женщины», что подкреплено Конституцией РФ и Концепции государственной семейной политики Российской Федерации на период до 2025 г. 
Отмечается также ориентация на сохранение брака, уважение к родителям и необходимость официального оформления брака.

Так, в Послании Президента Федеральному собранию отмечается, что «семья - это любовь, счастье, радость материнства и отиовства, что семья это крепкая связь нескольких поколений, где уважение к стариим и забота о детях всегда объединяют, дают чувство уверенности, защчщценности, надежности» [18].

Таким образом, при презентации семьи в аспекте традиционных ценностей выделяются несколько основных категорий, приведенных в табл. 1.

Таблица 1

Категории презентации семейных ценностей

(процент от общего числа упоминаний по каждой группе)

\begin{tabular}{|l|c|}
\hline \multicolumn{1}{|c|}{ Категории } & Доля упоминаний, \% \\
\hline «Традиционные семейные ценности» & \\
\hline $\begin{array}{l}\text { семья как одна из важных традиционных ценностей россий- } \\
\text { ского общества }\end{array}$ & 39,4 \\
\hline основа стабильности и безопасности государства & 13,4 \\
\hline основа единства российского общества & 20,2 \\
\hline источник сохранения культурных традиций & 15,4 \\
\hline духовная, моральная основа общества & 11,5 \\
\hline «Идеальный образ семьи и брака» & 9,6 \\
\hline зарегистрированный брак & 18,3 \\
\hline союз мужчины и женщины & 34,7 \\
\hline многодетная семья & 10,1 \\
\hline полная семья & 10,9 \\
\hline родительский авторитет и послушание & 12,2 \\
\hline ориентация на сохранение брака & 4,2 \\
\hline патриархальные отношения & \\
\hline
\end{tabular}

Основные способы легитимации необходимости внимания к традиционным семейным ценностям, особенно в официальном дискурсе, связан с демографическими проблемами, с которыми столкнулась Россия в последние десятилетия, и в этой связи с необходимостью социальной поддержки семей. При этом особую роль играют именно семьи с детьми, поэтому именно наличие детей является основным признаком «традиционной семьи»:

«Надо заботиться о детях и традиционной семье, в которой они появляются» [19].

Понимание идеального образа семьи как союза мужчины и женщины в первую очередь отрицает возможность официального закрепления однополых браков, которые рассматриваются как неприемлемые для нашей страны практики в отличие от многих зарубежных стран. Поэтому традиционные 
формы семьи представляются в качестве важных ценностных приоритетов для российского общества. Депутат Госдумы О. Баталина на совещании рабочей группы по поправкам в Конституцию отметила:

«Я не знаю, лет десять назад я точно не могла бы даже предположить, что на смену простым, понятным для нас словам «мама» $и$ «nапа» могут прийти какие-то универсальные странные понятия «родитель номер один» и «родитель номер два». Сегодня же это не фантастика, сегодня это реальность в ряде стран. Конечно, не в нашей стране» [17].

Основной оппозицией категории «традиционные семейные ценности» является недостаточное внимание по отношению к вопросам семьи и социальной политики в предыдущие периоды развития страны, а также недостаток бюджетных средств, который не позволял ранее и не всегда позволяет теперь оказывать социальную помощь семьям должным образом. Также в эти годы наблюдалось «западное влияние» на ценности россиян, которые, по мнению экспертов и политиков, несут угрозу безопасности страны не в меньшей степени, чем военные угрозы (табл. 2).

Таблица 2

Основные стратегии дискурса традиционных ценностей семьи по материалам российских СМИ 2006-2020 гг.

\begin{tabular}{|c|c|c|}
\hline $\begin{array}{l}\text { Стратегия } \\
\text { дискурса }\end{array}$ & Традиционные семейные ценности & Идеальная семья и брак \\
\hline Презентация & $\begin{array}{l}\text { - Семья как одна из важных тра- } \\
\text { диционных ценностей российского } \\
\text { общества } \\
\text { - Основа стабильности и безопас- } \\
\text { ности государства, его будущего } \\
\text { развития } \\
\text { - Основа единства российского } \\
\text { общества } \\
\text { - Источник сохранения культурных } \\
\text { традиций } \\
\text { - Духовная, моральная основа об- } \\
\text { щества }\end{array}$ & $\begin{array}{l}\text { - Зарегистрированный брак в рамках } \\
\text { гражданских или религиозных ин- } \\
\text { ститутов } \\
\text { - Союз мужчины и женщины } \\
\text { - Формирование полной многодетной } \\
\text { семьи (3 и более детей) } \\
\text { - Родительский авторитет и послу- } \\
\text { шание } \\
\text { - Ориентация на сохранение брака } \\
\text { - Патриархальные отношения } \\
\text { (в основном поддерживаются предста- } \\
\text { вителями РПЦ) }\end{array}$ \\
\hline Легит & $\begin{array}{l}\text { - Демографические вызовы } \\
\text { - Социальная политика в отношении } \\
\text { семьи и детей } \\
\text { - Необходимость оградить семейные } \\
\text { ценности от разрушения } \\
\text { - Семья как главная ценность для } \\
\text { большинства россиян } \\
\text { - Закрепленность семейных ценно- } \\
\text { стей в истории, религии и культуре }\end{array}$ & $\begin{array}{l}\text { - Упадок института брака и семьи, вы- } \\
\text { званный влиянием западных ценностей } \\
\text { - Необходимость поддержания главно- } \\
\text { го предназначения семьи - рождения } \\
\text { и воспитания детей } \\
\text { - Исторически закрепленные традиции } \\
\text { российской семьи; исторические, рели- } \\
\text { гиозные и культурные традициями } \\
\text { - Мнения большинства россиян в от- } \\
\text { ношении семейных отношений }\end{array}$ \\
\hline
\end{tabular}


Окончание табл. 2

\begin{tabular}{|c|c|c|}
\hline $\begin{array}{l}\text { Стратегия } \\
\text { дискурса }\end{array}$ & Традиционные семейные ценности & Идеальная семья и брак \\
\hline Оппозиция & $\begin{array}{l}\text { - Влияние западных ценностей, раз- } \\
\text { рушающих традиционную семью и } \\
\text { подрывающих единство российского } \\
\text { общества, рост терроризма, экстре- } \\
\text { мизма } \\
\text { - «Наследие прошлого», в основном } \\
90-\text { и и начала 2000-х, связанного с } \\
\text { недостаточным вниманием государ- } \\
\text { ства к нуждам семьи и ростом числа } \\
\text { разводов, незарегистрированных бра- } \\
\text { ков, абортов, сиротства и т.д. } \\
\text { - Бюджетные ограничения, препятст- } \\
\text { вующие достаточной поддержке семьи }\end{array}$ & $\begin{array}{l}\text { - Однополые семьи и гомосексуаль- } \\
\text { ные отношения в целом } \\
\text { - Отказ от рождения детей, аборты } \\
\text { - Разводы } \\
\text { - Вмешательство в дела семьи (юве- } \\
\text { нальная юстиция и криминализация } \\
\text { семейного насилия) } \\
\text { - Феминизм, эмансипация женщин }\end{array}$ \\
\hline
\end{tabular}

Наиболее устоявшимся стереотипом, используемым политиками и экспертами, является апелляция к сохранению стабильности и безопасности, которые обеспечивает крепкая многодетная семья. Противопоставление России и Запада, апелляция к внешним угрозам является популярным способом легитимации различных политических идей. С этим также взаимосвязана отсылка к необходимости «собственного пути», «самобытности» и особой российской духовно-ценностной основы, которая также «по определению» не должна вызвать сомнения у большинства аудитории и часто используется для обоснования традиционных ценностей семьи.

«Есть такое понятие «толерантность», но все-таки Россия должна жить по своим, а не западньм иенностям» [20].

Концепт «союз мужчины и женщины» представляется как наиболее соответствующий ценностным паттернам большинства россиян в рамках пpocmblx u понятных для нас слов «мама» $u$ «nana» [17], т.е. как приемлемых представлений для большинства представителей российского общества.

Таким образом, пропаганда значимости традиционных ценностей в основном осуществляется посредством государственных органов, а идеального образа семьи и брака - ресурсами гражданского общества.

Заключение. Критический дискурс-анализ является одним из наиболее плодотворных инструментов исследования репрезентации определенных видов ценностей в политических текстах. Дискурс традиционных семейных ценностей обеспечивается теми же инструментами, которые легитимизируют политику власти - стабильность, безопасность и порядок, централизацию власти: противопоставляются «лихим 90-м», предыдущим периодам упадка социальной политики, влиянию западных ценностей, угрожающих целостности и безопасности страны. Нормализация традиционных ценностей достигается посредством «на- 
турализации» и «закрепления» патриархальных устоев, отрицающих возможности разнообразия и не допуская существования иных моделей семьи, апелляции к «историческим корням», морали, религии, стабильности, единства и безопасности «народа». В этой модели превалирует инструментализация семьи, рассмотрение ее как пути для достижения целей государства. Наиболее упоминаемой категорией для характеристики идеального образа семьи является многодетная семья. Брак понимается как «союз мужчины и женщины», отмечается также ориентация на сохранение брака, уважение к родителям и необходимость официального оформления брака.

Следует отметить, что использование оппозиций в различных типах документов не однозначно. Так, в официальных документах и материалах, содержащих высказывания представителей власти, оппозиции не столь явно выражены. В основном в этих документах используются позитивные инструменты презентации и легитимации. Наиболее часто встречаются оппозиции, связанные с трудностями социальной поддержки семьи и наследием прошлого. В документах, содержащих мнения общественности - экспертов, представителей общественных организаций, в основном говорится о западных угрозах в виде пропаганды нетрадиционных отношений, гендерного равенства и вмешательства в дела семьи. Представители гражданского общества более активны в демонстрации негативного отношения к абортам и разводам и часто используют для этого апелляцию к религиозным ценностям россиян. Таким образом, пропаганда значимости традиционных ценностей в основном осуществляется посредством государственных органов, а идеального образа семьи и брака - ресурсами гражданского общества. Более сдержанное использование оппозиций или их отсутствие в официальном дискурсе говорит о том, что он транслирует в основном «положительное представление себя», в то время как дискурс гражданского общества более активен в демонстрации угроз традиционным ценностям, т.е. в основном транслирует «отрицательное представление других».

\section{Список литературы}

1. Хобсбаум Э. Изобретение традиций // Вестник Евразии. - 2000. - № 1. C. 47-62.

2. Universal Declaration of Human Rights [Электронный ресурс]. - URL: https:/www.ohchr.org/EN/UDHR/Documents/UDHR_Translations/eng.pdf (дата обращения: 7.03.2021).

3. Korostelina K.V. Understanding Values of Cultural Heritage within the Framework of Social Identity Conflicts // Values in Heritage management: emerging approaches and research directions: Journal of Heritage Tourism / ed. by E. Avrami, S. Macdonald, R. Mason, D. Myers. - 2020. - № 15:5. - P. 593-595. - Getty Publications Los Angeles, CA, 2020. 
4. Robertson R. Globalization: Social Theory and Global Culture. - Thousand Oaks, 1992. CA: Sage. -224 p.

5. Inglehart R., Baker W.E. Modernization, Cultural Change, and the Persistence of Traditional Values. American Sociological Review. - 2000. - Vol. 65, no. 1. Looking Forward, Looking Back: Continuity and Change at the Turn of the Millenium. - P. 19-51.

6. Jang Y., Ko Y., Kim S.Y. Cultural correlates of national innovative capacity: a cross-national analysis of national culture and innovation rates // Journal of open innovation. - 2016. - No. 2: 23. - P. 1-16.

7. Динамика ценностей и модернизация: опыт количественного анализа / Ю.В. Зинькина, Е.В. Слинько, Д.А. Быканова, А.В. Коротаев // Журнал социологии и социальной антропологии. - 2018. - № 21 (1). - С. 44-72.

8. Инглхарт Р., Вельцель К. Модернизация, культурные изменения и демократия: Последовательность человеческого развития. - М.: Новое издательство, 2011. - 464 с.

9. Ван Дейк Тён А. Дискурс и власть: Репрезентация доминирования в языке и коммуникации: пер. с англ. - М.: ЛИБРОКОМ, 2013. - 344 с.

10. Feurclough N. Discourse and social change. - Cambridge, Polity Press, 1992. $-258 \mathrm{p}$.

11. Wodak R. Critical Discourse Analysis // Continuum Companion to Discourse Analysis / ed. by Ken Hyland, Brian Paltridge. - London: Continuum, 2011. - P. 38-54.

12. KhosraviNik M. Actor descriptions, actor attributions, and Argumentation: toward a Systematization of CDA analytical Categories in their representation of Social groups // Critical discourse analysis. Vol. II / ed. by Ruth Wodak. - London: Sage, 2013. - P. 187-209.

13. Новый текст Конституции РФ с поправками 2020 [Электронный реcypc]. - URL: http:/duma.gov.ru/news/48953/ (дата обращения: 3.02.2021).

14. Акимов И. «Семья и все, что с ней связано - ключевая ценность для россиян». Почему важно дополнить положение в Конституции о социальном государстве и статусе семьи [Электронный ресурс] // Газета.ру. - 2020. 19 февр. - URL: https://www.gazeta.ru/social/2020/02/19/12967567.shtml (дата обращения: 18.10.2020).

15. Концепция государственной семейной политики Российской Федерации на период до 2025 года (общественный проект): в 3 ч. / сост. Е.Б. Мизулина [и др.]. - М., 2013. - Ч. 1. - 25 с.

16. Крашенинников П. Защитим семью - защитим детей [Электронный ресурс] // Рос. газ. - 2020. - 11 июня. - URL: https://rg.ru/2020/06/11/pavel-krasheninnikov-zashchitim-semiu-zashchitim-detej.html (дата обращения: 11.10.2020).

17. Встреча с рабочей группой по подготовке предложений о внесении поправок в Конституцию. 13 февр. 2020 г. [Электронный ресурс]. - URL: http://kremlin.ru/events/president/news/62776 (дата обращения: 16.01.2021). 
18. Послание Президента Федеральному собранию. 15.01.2020 [Электронный ресурс]. - URL: http://kremlin.ru/events/president/news/62582 (дата обращения: 13.08.2020).

19. Александр Котов о защите в Конституции традиционных семейных ценностей: Все остальное от лукавого [Электронный ресурс]. - URL: https:// m.pln24.ru/politics/371593.html (дата обращения: 22.08.2020).

20. Третьякова Н. Простое счастье. Почему нужно укреплять традиционные семейные ценности? [Электронный ресурс] // Аргументы и факты. - 2020. 23 июня. - № 26. - URL: https://tver.aif.ru/society/prostoe_schaste_pochemu_nuzhno_ukreplyat_tradicionnye_semeynye_cennosti (дата обращения: 22.08.2020).

\section{References}

1. Hobsbawm E. Invented tradition (Russ. ed.: Hobsbaum E. Izobretenie traditsii. Vestnik Evrazii, 2000, no. 1, pp. 47-62).

2. Universal declaration of human rights. Available at: https://www.ohchr.org/ EN/UDHR/Documents/UDHR_Translations/eng.pdf(accessed 07.03.2021).

3. Korostelina K.V. Understanding values of cultural heritage within the framework of social identity conflicts. Values in Heritage management: Emerging approaches and research directions: Journal of Heritage Tourism. Eds. E. Avrami, S. Macdonald, R. Mason, D. Myers. Getty Publications, Los Angeles, CA, 2020, no. $15: 5$, pp. 593-595.

4. Robertson R. Globalization: Social theory and global culture. Thousand Oaks, CA: Sage, 1992, 224 p.

5. Inglehart R., Baker W.E. Modernization, cultural change, and the persistence of traditional values. American Sociological Review. Looking Forward, Looking Back: Continuity and Change at the Turn of the Millenium, 2000, vol. 65, no. 1, pp. 19-51.

6. Jang Y., Ko Y., Kim S.Y. Cultural correlates of national innovative capacity: A cross-national analysis of national culture and innovation rates. Journal of Open Innovation, 2016, no. 2: 23, pp. 1-16.

7. Zin'kina Iu.V., Slin'ko E.V., Bykanova D.A., Korotaev A.V. Dinamika tsennostei i modernizatsiia: opyt kolichestvennogo analiza [Dynamics of values and modernization: A quantitative analysis]. Zhurnal sotsiologii i sotsial'noi antropologii, 2018, no. 21 (1), pp. 44-72.

8. Inglehart R., Welzel C. Modernization, cultural change, and democracy: The human development sequence (Russ. ed.: Inglkhart R., Vel'tsel' K. Modernizatsiia, kul'turnye izmeneniia i demokratiia: posledovatel'nost' chelovecheskogo razvitiia. Moscow, Novoe izdatel'stvo, 2011, 464 p.).

9. Dijk, Teun A. van. Discourse, power and access (Russ. ed.: Van Deik Ten A. Diskurs i vlast': reprezentatsiia dominirovaniia v iazyke i kommunikatsii. Moscow, LIBROKOM, 2013, 344 p.). 
10. Feurclough N. Discourse and social change. Cambridge, Polity Press, 1992, $258 \mathrm{p}$.

11. Wodak R. Critical discourse analysis. Continuum Companion to Discourse Analysis. Eds. Hyland K., Paltridge B. London, Continuum, 2011, pp. 38-54.

12. KhosraviNik M. Actor descriptions, actor attributions, and argumentation: toward a systematization of CDA analytical categories in their representation of social groups. Critical discourse analysis. Ed. R. Wodak. London, Sage, 2013, vol. 2, pp. 187-209.

13. Novyi tekst Konstitutsii RF s popravkami 2020 [New text of the RF Constitution]. Available at: http://duma.gov.ru/news/48953/ (accessed 03.02.2021).

14. Akimov I. "Sem'ia i vse, chto s nei sviazano - kliuchevaia tsennost' dlia rossiian". Pochemu vazhno dopolnit' polozhenie v Konstitutsii o sotsial'nom gosudarstve i statuse sem'i [Family and all related things are the key values for Russians. Why it is important to include in the Constitution the provision on social state and family status]. Gazeta.ru, 2020, available at https://www.gazeta.ru/ social/2020/02/19/12967567.shtml (accessed 19.02.2020).

15. Kontseptsiia gosudarstvennoi semeinoi politiki Rossiiskoi Federatsii na period do 2025 goda (obshchestvennyi proekt) [Concept of the state family policy in Russian Federation]. Part 1. Eds. E.B. Mizulina. Moscow, 2013, 25 p.

16. Krasheninnikov P. Zashchitim sem'iu - zashchitim detei [Protect family protect children]. Rossiiskaia gazeta, available at: https://rg.ru/2020/06/11/pavelkrasheninnikov-zashchitim-semiu-zashchitim-detej.html (accessed 11.10.2020).

17. Vstrecha s rabochei gruppoi po podgotovke predlozhenii o vnesenii popravok v Konstitutsiiu. 13 fevralia 2020 g. [Meeting of the working group to prepare amendments to the Constitution dated 13/02/2020]. Available at: http://kremlin.ru/events/president/news/62776 (accessed 16.01.2021).

18. Poslanie Prezidenta Federal'nomu sobraniiu. 15.01.2020 [The Presidential Address to the Federal Assembly dated 15/01/2020]. Available at: http://kremlin.ru/events/president/news/62582 (accessed 13.08.2020).

19. Aleksandr Kotov o zashchite v Konstitutsii traditsionnykh semeinykh tsennostei: Vse ostal'noe ot lukavogo [Alexander Kotov on traditional family values protection: All of the rest is from devil]. Available at: https://m.pln24.ru/politics/371593.html (accessed 22.08.2020).

20. Tret'iakova N. Prostoe schast'e. Pochemu nuzhno ukrepliat' traditsionnye semeinye tsennosti? [Simple happiness. Why it is necessary to support traditional family values]. Argumenty $i$ fakty, 2020, no. 26, available at: https://tver.aif.ru/society/prostoe_schaste_pochemu_nuzh-no_ukreplyat_tradicio nnye_semeynye_cennosti (accessed 22.08.2020).

Оригинальность $82 \%$

Получено 19.04.2021 Принято 11.05.2021 Опубликовано 30.09.2021 
M.N. Makarova

\section{REPRESENTATION OF “TRADITIONAL VALUES” \\ IN THE RUSSIAN PUBLIC POLITICAL DOMAIN \\ (AS EXEMPLIFIED BY THE DISCOURSE ANALYSIS \\ OF FAMILY VALUES)}

The author considers the main approaches to the study of traditional values. In the framework of socio-philosophical analysis, the following characteristics of traditional values have been identified: their relative invariance, connection with past, intention to support social concertation. Sociological dimension can be represented as a group of values typical of different social and cultural groups and as characteristics of specific types of attitudes, historically determined and linked with the past. Political and ideological aspect includes considering traditional values as a ground for social and political discourse that is dedicated to build ideology and credibility of authority, social mobilization and propaganda. To analyze political texts representing family in the context of traditional values, the content analysis and critical discourse analysis were applied. The analysis demonstrated that documents reflecting the authorities' position include oppositions connected with complications of supporting families and legacy of the past. The texts manifesting the civil society's opinions mainly touch upon western threats in the form of propaganda of non-traditional relationships, gender equality and intervention into the family issues. A moderate expression of oppositions or their absence in official discourse indicates that this type of discourse mostly reproduces "a positive self-presentation", while the civil society discourse incorporates "a negative presentation of others".

Keywords: traditional values, family, marriage, critical discourse analysis.

Marina N. Makarova - Doctor of Sociology, Professor, Department of Sociology, Udmurt State University, Izhevsk, Russia, e-mail: makmar11@mail.ru.

Received 19.04.2021 Accepted 11.05.2021 Published 30.09.2021 